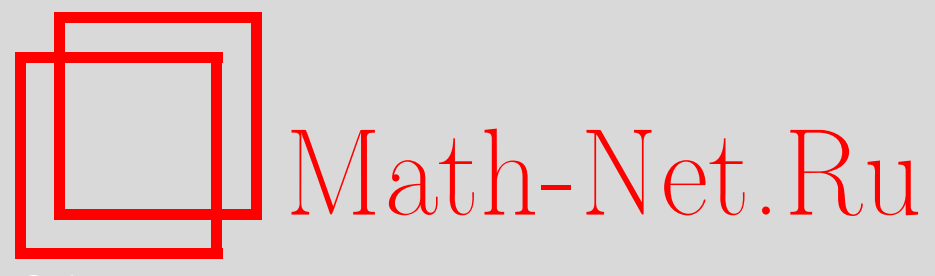

С. Гандилян, Атмосфера Земли и современная энергетика, Квант, 2021, номер 11, 5-11

DOI: https://doi.org/10.4213/kvant20211102

Использование Общероссийского математического портала Math-Net.Ru подразумевает, что вы прочитали и согласны с пользовательским соглашением http://www . mathnet.ru/rus/agreement

Параметры загрузки:

IP: 3.85 .73 .92

26 апреля 2023 г., 14:12:00

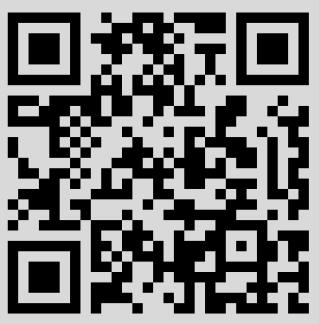




\section{Атмосфера Земли \\ и современная энергетика}

\section{С.ГАНДИЛЯН}

$\Pi$ РОБЛЕМА ЗАГРЯЗНЕНИЯ ОКРУжающей природной среды является важнейшей экологической проблемой современности как с точки зрения непосредственно загрязнения природы, так и из-за влияния повышающейся концентрации парниковых газов в атмосфере на климат Земли.

В 2021 году Нобелевская премия по физике (точнее, половина премии) была присуждена климатологам Клаусу Хассельману и Сюкуро Манабэ за «моделирование физики климата Земли, математическое описание изменчивых систем и точное предсказание глобального потепления» . Манабэ был одним из первых исследователей, указавших на влияние увеличивающейся концентрации углекислого газа в атмосфере на земной климат. Он же в 1960-х годах руководил разработкой первых компьютерных физических моделей климата. Спустя примерно десять лет после первых результатов Манабэ, Клаус Хассельманн создал свою модель, связавшую воедино хаотичную и сложно предсказуемую локальную погоду и глобальный климат, а также предложил методику, позволившую доказать ключевую роль человека в происходящих сейчас быстрых климатических изменениях.

Основной вывод исследований ученых таков: на сегодняшний день определяющий вклад в обострение этой проблемы вносит современная промышленная энергетика. Помимо энергетики существенное негативное влияние на окружающую среду оказывают современная строительная индустрия, промышленные объекты разного предназначения, транспорт, сельское хозяйство и другие области жизнедеятельности человека.

DOI: https://doi.org/10.4213/kvant20211102

\section{Глобальное потепление: миф или реальность?}

С точки зрения условий жизни человека и эволюции биосферы в целом, атмосфера Земли представляет особый интерес в двух отношениях .

Во-первых, совокупность процессов мас$\mathrm{co}^{-}$, энерго- и теплопереноса, протекающих в атмосфере, а также взаимодействие атмосферы с океанами, сушей и шапками льда на полюсах Земли определяют погоду (например, в средних широтах Земли любое изменение погоды вызывается в основном атмосферными явлениями, в то время как погода в тропиках определяется взаимодействием атмосферы и океана) и климат - как устойчивую характеристику погодных особенностей отдельных континентов, климатических поясов, горных хребтов и прочих географических объектов в течение многих десятков лет. Вовторых, химический состав атмосферы жизненно важен для человека, а также для животного и растительного мира в целом.

Эпоха научно-технического и технологического прогресса в середине XIX века ознаменовалась началом климатических изменений, связанных с повышением глобальной температуры на Земле, т.е. температуры поверхности Земли, осредненной по географическим координатам, времени суток и сезону. Глобальная температура характеризует термо-энергетическое состояние системы Земля-атмосфера в целом, так что ее изменение с годами определяет эволюционный путь теплового состояния самой планеты.

Рисунок 1 иллюстрирует, как менялась глобальная температура Земли за последние 160 лет. Начиная примерно с 1860 года - времени первых инструментальных замеров приземной температуры возду- 


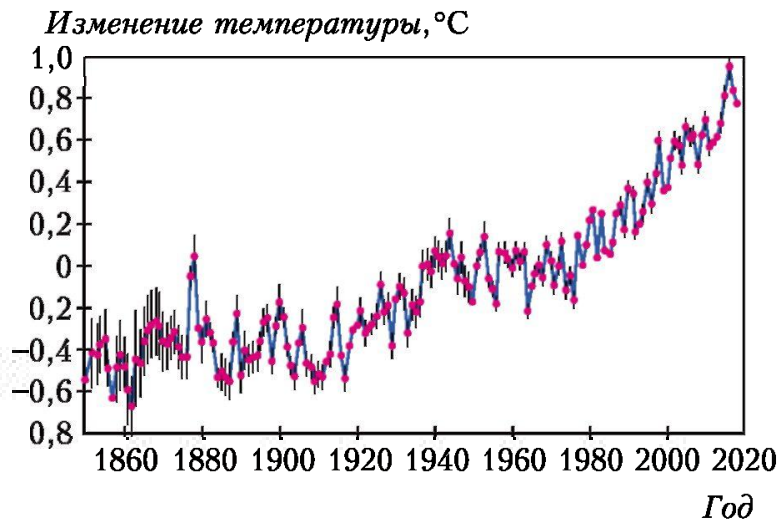

Рис. 1. График изменения глобальной температуры Земли. За ноль взята средняя температура за 19511980 годы

ха - вплоть до настоящего времени отмечается постепенный рост температуры на Земле. По данным Всемирной метеорологической организации, глобальное повышение температуры за период с 1860 по 2020 год составило около $\Delta T=0,9^{\circ} \mathrm{C}$. При этом рост температуры все эти годы шел неравномерно. Достаточно стабильный медленный подъем отмечался в 1860-1940 годах, когда температура воздуха возросла на $0,4^{\circ} \mathrm{C}$. Далее в течение $1940-1980$ годов отмечался этап умеренных колебаний средних годичных температур без какого-либо заметного тренда. За этим последовал период - с 1980 года до настоящего времени - быстрого подъема глобальной температуры, прирост которой составил еще $0,5^{\circ} \mathrm{C}$. В $1980-\mathrm{x}$ - середине $1990-\mathrm{x}$ годов был отмечен ряд исключительно тепльх сезонов, а 1998 год оказался экстремально тепльм за весь период проведения температурных измерений на Земле.

На сегодняшний день открытым остается вопрос о том, негативное изменение климата и наблюдаемое глобальное потепление обусловлено действиями человека, вызвано неподконтрольными нам силами природы или является сочетанием разных факторов. Несмотря на существование различных точек зрения на причины этого явления, сам факт глобального потепления на Земле является неоспоримым (по данным ЮНЕСКО, только за последние десять лет средняя температура на планете повысилась на $0,3{ }^{\circ} \mathrm{C}$ ). Изменение температуры воздуха вызывает развитие ряда динамических процессов в геосферных и гидросферных оболочках Земли, способных оказать как положительное, так и отрицательное воздействие на окружающую нас природную среду. С последним связано существенное снижение безопасности и рост ущерба от стихийных бедствий. Так, по расчетам американских специалистов потепление атмосферы на $1^{\circ} \mathrm{C}$ может привести к усилению воздушных потоков на Атлантическом побережье США на 40$60 \%$, что, несомненно, усугубит и без того достаточно высокую уязвимость этой территории от тропических тайфунов и ураганов.

С каждым годом все большее значение для экологии планеты приобретает тепловое загрязнение. Если до середины прошлого века промьшленная деятельность человека не вызывала особой тревоги, то в последние десятилетия вторая волна усиления глобального потепления заставляет по-другому смотреть на тепловое загрязнение, ставя его на одно из первых мест среди негативных последствий человеческой хозяйственной деятельности. Промышленные объекты, в том числе и объекты производства энергоресурсов, могут быть ответственны за возникновение глобальных, региональных и локальных (местных) әкологических проблем. Но основным глобальным негативным воздействием промышленной энергетики на окружающую среду считается выброс в атмосферу парниковых газов.

Масштабы современной промышленной энергетики пока еще малы в рамках природного энергетического баланса: потребление энергии человечеством составляет всего около двух десятитысячных от суммарного поступления әнергии солнечного излучения, мощность которого составляет примерно 1,7 · $10^{14}$ кВТ. Вместе с тем, мировая промышленная энергетика соизмерима с энергией, идущей на процессы фотосинтеза органики, и по оценкам достигает около $30 \%$ от нее. А это указывает на принципиальную возможность заметного 
влияния энергетики на физико-химические и оптические свойства атмосферы. И влияние это может проявиться различным образом. С одной стороны, изменение оптических свойств атмосферы может изменить обмен лучистой энергией между атмосферой и поверхностью Земли, с другой стороны, вызванное человеческой деятельностью изменение физико-химических свойств атмосферы может отразиться на состоянии биосферы, меняя к худшему условия жизни всего живого мира.

Возникает естественный вопрос: какие предельные производственные технические и технологические мощности можно использовать на поверхности Земли, не нарушая тепловой и экологический баланс биосферы?

\section{Атмосфера и тепловой баланс системы Земля-атмосфера}

Атмосферу Земли условно делят на две части: верхнюю и нижнюю. Верхние и нижние атмосферные слои взаимодействуют между собой посредством разнообразных электрофизических, газодинамических и химических процессов, образуя сложную систему, подверженную воздействиям как солнечных, так и земных глобальных әнергетических процессов.

Нижняя часть атмосферы состоит из двух слоев с условными границами. Устремляясь ввысь от поверхности Земли, сначала попадаем в тропосферу, где мы живем и где идут дожди, падает снег, плавают облака, бывают бури и грозы т.е. все, что входит в понятие погоды и климата. Тропосфера простирается до высоты 12-15 км. Выше начинается стратосфера, она имеет верхнюю границу на высоте 45-50 км, и температура стратосферы с ростом высоты падает. Здесь расположен слой с максимальной концентрацией ионов и молекул озона $\mathrm{O}_{3}$ (на высоте 20-50 км), который защищает на Земле все живое от губительных ультрафиолетовых лучей. Между тропосферой и стратосферой имеется тонкий переходный слой, именуемый «тропопаузой».

Состав нижней атмосферы не всегда был такой, какой мы его видим сейчас. В начальной стадии развития Земли и эволюционных процессов в биосфере атмосфера не содержала свободного кислорода: он входил в состав углекислого газа. Анализ горных пород Земли показывает, что современный состав атмосферы создали живые организмы: свободный кислород начал появляться в атмосфере примерно 1,8 млрд лет назад (возраст Земли около 4,6 млрд лет) в результате действия микроорганизмов (бактерий), перерабатывающих углекислый газ в кислород, наличие которого привело к возникновению озонного пояса. Создались условия для появления разнообразных живых организмов и растений, жизнедеятельность которых связана с переработкой под действием солнечной энергии углекислого газа атмосферы в углерод органических веществ и в кислород. Нижняя атмосфера состоит в основном из азота $(\approx 78,08 \%)$, кислорода $(\approx 20,9 \%)$, аргона $(\approx 0,9 \%)$ и смеси в малых количествах углекислого газа, неона, гелия, метана, криптона, которые оптически прозрачны для инфракрасного излучения.

Верхней атмосферой называют внешнюю часть газовой оболочки Земли, простирающуюся от высот порядка 50-60 км до расстояний в несколько десятков земных радиусов $\left(R_{3} \approx 6370\right.$ км$)$. Верхнюю атмосферу условно подразделяют на ряд перекрывающихся слоев с нерезкими границами: мезосфера $(50$ км $<R<150$ км), термосфера (150 км $<R<1000$ км), экзосфера (1000 км $<R<1500$ км), ионосфера $(1200$ км $<$ $<R<1800$ км), плазмосфера (1600 км $<R<$ $\left.<4 R_{3}\right)$, магнитосфера $\left(4 R_{3}<R<30 R_{3}\right)$, причем три первые сферы связывают с нейтральными частицами, а три последующие - с заряженными, а именно ионами и электронами, образовавшимися в результате ионизации атомов и молекул солнечным излучением или частицами высоких энергий.

Знания о состоянии верхней атмосферы, умение прогнозировать его изменения необходимы человечеству в такой же степени, как прогноз погоды и климата, определяемых состоянием нижней атмосферы. От складывающихся в верхней атмосфере 
условий в некоторых узловых областях жизнедеятельности современной цивилизации зависит очень многое, в частности работа всевозможных систем радиосвязи, надежность линий электропередач и... даже здоровье человека. Космическую погоду нужно предсказывать не только для того, чтобы предупредить об угрозе спутникам или космонавтам. Например, интенсивные потоки заряженных частиц в ионосфере индуцируют сильные электрические токи на поверхности Земли, которые могут создать аварийные ситуации для газопроводов, систем навигации и связи, трансформаторных подстанций, высоковольтных линий электропередачи и т.д.

Чтобы оценить влияние человеческой деятельности на окружающую среду, необходимо выяснить, какие энергетические процессы происходят в атмосфере и на поверхности Земли и какое участие в них принимает или может принять человек. При этом будем учитывать некоторые эмпирические факты космического наблюдения об энергетике воздействия солнечного излучения электромагнитной энергии на систему Земля-атмосфера.

Общеизвестно, что при прохождении солнечного излучения через земную атмосферу одновременно происходят три процесса энергопреобразования:

1) отражение около $34 \%$ солнечного излучения обратно в космос (облаками и самой атмосферой);

2) поглощение около $19 \%$ солнечного излучения атмосферой, когда әнергия перерабатывается атмосферой и излучается обратно в космическое пространство в виде теплового (инфракрасного) излучения;

3) пропускание около $47 \%$ солнечного излучения на поверхность Земли и отражение около $20 \%$ его обратно в космос в виде инфракрасного излучения.

В результате всего $27 \%$ солнечного излучения, поступающего на Землю из космического пространства в целом, преобразуется в энергию, которая идет на испарение и нагрев воды, нагрев атмосферы, образование ветров, волн, течений и т.п.

Если предположить, что преобразование тепловой энергии в работу происходит в обратимых процессах, то коэффициент полезного действия $\eta$ природной тепловой машины Солнце-атмосфераЗемля, рабочим телом которой является атмосфера Земли, определяется по известной формуле

$$
\eta=\frac{T_{\mathrm{C}}-\boldsymbol{T}_{\mathrm{B}}}{T_{\mathrm{C}}} .
$$

Здесь $T=t+273-$ температура по шкале Кельвина, $t_{\mathrm{C}} \approx 6200^{\circ} \mathrm{C}-$ средняя температура поверхности Солнца и $t_{3} \approx 15^{\circ} \mathrm{C}-$ средняя температура поверхности Земли, которые выражаются в градусах Цельсия. Если в процессе прихода и ухода преобразованного солнечного излучения существующий энергетический баланс в системе Земля-атмосфера в целом не меняется, то и климат на Земле не меняется. А изменение климата происходит в результате нарушения энергетического баланса.

Из рисунка 2 видно, какую роль играет атмосфера как источник инфракрасного излучения в тепловом балансе системы Земля-атмосфера. Будем считать, что излучение и поглощение в инфракрасной части спектра происходят в нижней атмосфере высотой несколько десятков километров, где сосредоточена практически вся ее масса. Нижний и наиболее плотный

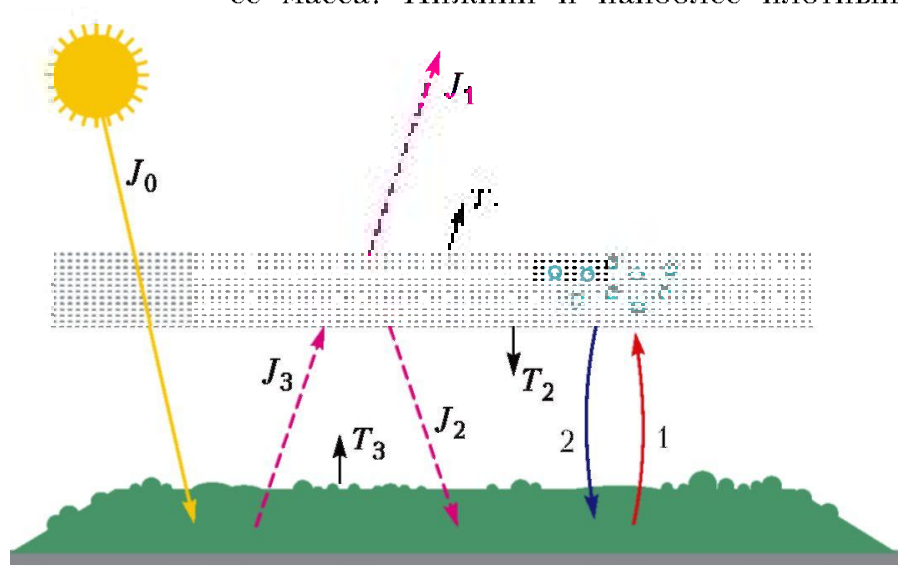

Рис. 2. Схематическая иллюстрация теплового баланса системы Земля-атмосфера 
слой (тропосфера), простирающийся до высот порядка 8-10 км в высоких широтах и до 16-18 км в экваториальном поясе, содержит около 80\% массы всей атмосферы и характеризуется почти линейным распределением (уменьшением) температуры с высотой. Допустим также, что тепловые потоки равномерно распределены по поверхности Земли, т.е. все основные энергетические процессы усреднены, и что в области инфракрасного спектра Земля и атмосфера излучают как абсолютно черное тело (что достаточно хорошо отражает реальность). А это излучение подчиняется закону Стефана-Больцмана: энергия, испускаемая с единицы поверхности абсолютного черного тела в единицу времени, равна $J=\sigma T^{4}$, где $\sigma=5,87 \cdot 10^{-8} \mathrm{BT} /\left(\mathrm{m}^{2} \cdot \mathrm{K}^{4}\right)-$ постоянная Стефана-Больцмана, а $T$ температура поверхности излучателя в кельвинах.

Условие теплового равновесия системы Земля-атмосфера выражается следующими уравнениями:

$$
\begin{gathered}
J_{0}=J_{1}, \\
J_{0}+J_{2}=J_{3} .
\end{gathered}
$$

Здесь $J_{0}-$ поток солнечного излучения, сосредоточенный в оптической части спектра и свободно проходящий через атмосферу; $J_{1}=\sigma T_{1}^{4}-$ поток инфракрасного излучения атмосферы за пределы Земли, $T_{1}$ - температура верхней части излучающего слоя приповерхностного слоя атмосферы; $J_{2}=\sigma T_{2}^{4}-$ поток излучения атмосферы на поверхность Земли, $T_{2}$ - температура приповерхностного слоя атмосферы; $j_{3}=\sigma T_{3}^{4}-$ поток инфракрасного излучения, испускаемого поверхностью Земли, $T_{3}$ - средняя температура поверхности Земли.

Поскольку температура нижней атмосферы убывает с высотой $\left(T_{2}>T_{1}\right)$, то $J_{2}>J_{1}$. Следует отметить, что $T_{1}$ и $T_{3}$ определяются не только радиационным излучением, как механизмом передачи тепла, но и другими процессами, главным из которых является конвективный перенос тепла из нижнего и плотного слоя атмосферы в стратосферу. Теплый воздух легче холодного, поэтому он поднимается вверх, а холодный опускается (на рисунке 2 это стрелки 1 и 2 соответственно) - возникает конвекция. Теплый воздух несет с собой от поверхности Земли водяной пар - важный парниковый газ. Чем теплее воздух, тем больше он может «вместить» молекул воды. Поднимаясь и остывая, пар конденсируется - так формируются облака.

Из условия $J_{2}>J_{1}$ следует, что $\sigma T_{3}^{4}>2 J_{0}$, или $T_{3}>1,2\left(J_{0} / \sigma\right)^{1 / 4}$. Если представить, что атмосфера Земли отсутствует или же она оптически прозрачна в инфракрасной области спектра, то условие теплового равновесия Земли с окружающим пространством дает $J_{0}=\sigma T_{3}^{4}$, т.е. $T_{3}=\left(J_{0} / \sigma\right)^{1 / 4}$. Получается, что присутствие атмосферы приводит к нагреванию поверхности Земли, так как создается дополнительный поток энергии и полная мощность энергии, принимаемой поверхностью Земли, существенно превышает мощность энергии, посылаемой на Землю Солнцем. Такое явление носит название парникового эффекта. Свое название эффект получил по явлениям в теплицах, перекрытых стеклянными крышами, поскольку стекло тоже легко пропускает солнечное излучение в видимой части спектра, но задерживает инфракрасное. Однако главный эффект всех теплиц и парников в другом - в предотвращении конвективного перемешивания заполняющего их воздуха с наружным воздухом: как только открываются окна теплиц и восстанавливается связь с внешним пространством, сразу же пропадает и парниковый әффект.

\section{Влияние загрязнения атмосферы на тепловой баланс}

На сегодняшний день насущным является такой вопрос: какие предельные мощности искусственных источников тепловой энергии можно вырабатывать на поверхности Земли, не нарушая тепловой баланс системы Земля-атмосфера?

В современной научной литературе принято считать, что необратимые процессы в биосфере могут начаться после повышения средней температуры поверхности 
Земли примерно на 1,5 градуса. Оценим, какие дополнительные мощности теплового излучения, выделяемые на поверхности Земли, приведут к изменению ее температуры на $\Delta T \approx 1,5$ град.

При повышении температуры поверхности Земли на величину $\Delta T$ поток инфракрасного излучения, испускаемого с поверхности Земли, определяется (согласно закону Стефана-Больцмана) по формуле

$$
J_{3}=\sigma\left(T_{3}+\Delta T\right)^{4} \approx \sigma T_{3}^{4}\left(1+\frac{4 \Delta T}{T_{3}}\right) .
$$

Соответственно, относительное изменение потока испускаемого излучения будет равHO

$$
\frac{\Delta J_{3}}{J_{3}} \approx \frac{4 \Delta T}{T_{3}} .
$$

Мощность потока инфракрасного излучения, испускаемого поверхностью Земли, составляет

$$
W \approx J_{3} S \approx 4 \pi R_{3}^{2} J_{3},
$$

где $R_{3} \approx 6370$ км - средний радиус Земли. Если считать, что средняя температура поверхности Земли $T_{3} \approx 288 \mathrm{~K}$, то получается, что $W \approx 2,2 \cdot 10^{14}$ кВт. А значит, при появлении на Земле дополнительных источников энергии мощностью $\Delta W \approx$ $\approx 3,6 \cdot 10^{12}$ кВт температура поверхности Земли поднимается на $\Delta T \approx 1,5$ град.

Современная мощность әнергии, вырабатываемой на Земле, достигла величины $0,5 \cdot 10^{10}$ кВт. Если сохранится рост мировой энергетики, наблюдаемый в последние десятилетия (5-7\% в год), то величина $\Delta W$ будет достигнута в конце настоящего столетия. При этом следует отметить одно важное обстоятельство. Полученная оценка $\Delta W$ является справедливой, если современная әнергетика не связана с процессами, происходящими при поглощении и испускании әнергии Землей. Но так как эта энергетика частично вписывается в общий цикл әнергетических процессов с участием Земли, то предельное значение вырабатываемой мощности значительно выше приведенной оценки.

Один из наиболее возможных путей воздействия человека на климат Земли может быть связан с искусственным изменением оптических свойств нижней атмосферы. Особенность современной атмосферы Земли заключается в том, что основные ее компоненты - азот, кислород и аргон прозрачны как в оптической, так и в инфракрасной части спектра. Поэтому излучательные и поглощательные свойства атмосферы определяются газами, которые присутствуют в атмосфере в малых количествах, и примесями.

В инфракрасной области спектра излучательные свойства атмосферы в основном обусловлены соответствующими переходами из одного энергетического состояния в другое молекул воды $\left(\mathrm{H}_{2} \mathrm{O}\right)$, углекислого газа $\left(\mathrm{CO}_{2}\right)$ и озона $\left(\mathrm{O}_{3}\right)$. Атмосферный озон поглощает жесткое ультрафиолетовое излучение с частотой больше $10^{15}$ Гц, которое, как мы знаем, пагубно действует на живые организмы. Кроме того, атмосферный озон частично поглощает солнечное излучение в ультрафиолетовой и оптической областях спектра, тем самым обеспечивая повышение температуры в стратосфере и мезосфере (на высотах 2030 км). Проблема атмосферного углекислого газа заключается в выяснении причин его накопления в атмосфере. Непрерывный мониторинг атмосферного углекислого газа, проводимый учеными, показывает, что концентрация молекул углекислого газа в атмосфере монотонно увеличивается (если не учитывать сезонных осцилляций).

В основном имеются два механизма для роста концентрации углекислого газа. Вопервых, в результате добычи и использования горючих ископаемых (угля, нефти, природного газа, торфа) углерод из недр Земли включается в равновесие между углекислым газом атмосферы и связанным углеродом на поверхности Земли. Тем самым, увеличивается и масса углекислого газа в атмосфере. Во-вторых, вырубание и горение лесов приводит к уменьшению скорости фотосинтеза и, соответственно, к увеличению массы углекислого газа в атмосфере.

Возникает важный вопрос: при каких конщентрациях примеси это влияние станет заметным и может отразиться на теп- 
ловом балансе системы Земля-атмосфера? Для оценочных расчетов будем считать, что спектр молекул, которые добавляются в атмосферу в результате человеческой деятельности, не перекрывается со спектром поглощения молекул других компонентов природной атмосферы, т.е. до введения добавки атмосфера прозрачна в той области длин волн, которые әффективно поглощает и излучает эта компонента. Появление рассматриваемой молекулярной добавки приводит к тому, что некоторая доля этого излучения поглощается атмосферой, а затем, после высвечивания возбужденных молекул, частично возвращается на поверхность Земли, т.е. увеличиваются әнергия, поглощаемая поверхностью Земли, и температура самой поверхности.

Оценим, какая концентрация примеси обеспечивает повышение температуры поверхности Земли на $\Delta T$ градусов. За счет примеси на поверхность Земли в единицу времени попадает энергия инфракрасного излучения, равная

$$
\frac{N(x) h \omega}{2 \pi}
$$

где $N(x)$ - концентрация излучающих молекул примеси на высоте $x$ рассматриваемого слоя атмосферы над поверхностью Земли, $1 / \tau$ - частота высвечивания возбужденной молекулы, $h \omega-$ энергия испускаемого фотона, $h$ - постоянная Планка, $\omega$ - частота центра зоны максимального излучения молекул добавки (множитель $\frac{1}{2}$ учитывает, что только половина испускаемых фотонов направляется в сторону Земли). Плотность потока дополнительного излучения за счет примеси будет равна

$$
\begin{gathered}
\Delta J_{3}=\frac{h \omega}{2 \tau} \int_{!}^{\dot{L}} N(x) d x, \\
N(x)=N(0) \exp \left(-\frac{h \omega}{2 \tau}\right)
\end{gathered}
$$

(здесь $N(0)$ - плотность возбужденных молекул примеси у поверхности Земли, $L$ - высота нижней атмосферы). С учетом связи относительного изменения плотности потока дополнительного излучения $\Delta J_{3}$ с полным потоком $J_{3}$ получаем

$$
4 J_{3} \frac{\Delta T}{T_{3}}=\frac{h \omega}{2 \tau} \int_{i:}^{L} N(0) \exp \left(-\frac{h \omega}{2 \tau}\right) d x .
$$

Это соотношение устанавливает связь между концентрацией молекул примеси на поверхности Земли $N(0)$ и изменением температуры поверхности $\Delta T$, которая создается этой примесью.

Таким образом, мы видим, что состояние Земли как открытой энергосистемы сильно зависит от атмосферы. Загрязнение атмосферы человеком при современном производстве в состоянии изменить тепловой баланс системы Земля-атмосфера. Например, климат больших городов в настоящее время заметно отличается от климата окружающей его местности, что связано как с дополнительным выделением энергии, так и с изменением состава расположенной над городом атмосферы. Исследования атмосферы и климата больших городов (особенно мировых промышленных центров) позволяет установить тенденции изменения климата всей Земли под влиянием человеческой деятельности и постараться предотвратить нежелательные изменения климата.

\section{Вниманию наших читателей}

Подписаться на журнал “Квант» можно с любого номера в любом почтовом отделении. Наш подписной индекс в каталоге "Пресса России» - 90964.

Купить журнал "Квант» возможно в магазине «Математическая книга» издательства МЦНМО (адрес интернет-магазина: bibliomcсmе.ru), а также в московских книжных магазинах "Библио-глобус", "Молодая гвардия», "Московский дом Книги» и в редакции журнала.

Архив вышедших номеров журнала “Квант» имеется на сайте http:/ / kvant.ras.ru 